\title{
Employment Relations And Bullying In Academia: A Case Of Academic Staff At Makerere University
}

Umar Kakumba, Makerere University, Uganda Robert Wamala, Makerere University, Uganda Seperia B. Wanyama, Makerere University, Uganda

\begin{abstract}
While institutions of higher learning are ordinarily believed to be the epitome of knowledge and custodians of focal principles that guide sound practices and performance, they are certainly not immune to the prowl of bullying and mobbing, which are antecedents to poor employment relations. This article presents results of a study conducted to examine the nature of employment relations and the prevalence of bullying amongst academic staff at Makerere University. It analyses the prevalence, perceptions, and manifestations of bullying; the nature of employment relations and the existing supportive systems to deal with the vice at this premier university of the eastern and central African region.

Results show that bullying and mobbing exist in University academic units. It has thrived on deficiencies in legal and policy framework, poor leadership styles and centralised control of decision-making, the nature of the working environment characterised by scanty resources and facilitation support to task holders. In spite of its incessant nature, it is often trivialized and relegated as a non-issue that deserve little, if any, serious attention. The authors posit that tolerating a culture of human abuse in any form undermines the very essence of a higher institution of learning. Thus, the university must develop a respectful organizational culture that fortifies colleagueship and harmonious coexistence through policy and open systems of communication with empowerment and participatory decision-making. Effort should be made to invigorate rigorous academic debate, research, and other scholarly endeavours, that promote intellectual resonance, as opposed to schemes of undermining practices.
\end{abstract}

Keywords: Employment Relations; Bullying; Makerere University; Employee Empowerment

\section{INTRODUCTION}

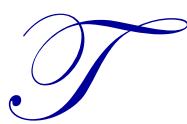

he world of work remains central to the lives of individuals, but at the same time, individual employees are central to organizational achievement. The need to promote and sustain effective organizational culture requires scrutiny of the conditions of work and how people are treated in a workplace. It signifies that the work people do must be enhanced and the relationship between individuals and organization, on the one hand, and between superiors and subordinates, on the other hand, must be harmonized for the overall success of the organisation.

Modern organizational performance thrives on the character of employment relations, which derives from communication and employee support practices that create leverage for the subordinate to innovate and make decisions. However, the above elements continue to elude modern organisations and bullying continues to thrive (Jaw \& Lui, 2003; Lopez et al., 2006). Ironically, institutions of higher learning are not immune to bullies (Cassell, 2011), despite the perception that their academic stature and intellectualism will lessen tendencies of harassment and discrimination. 
Considerable research has been undertaken on workplace bullying (Casimir, 2012; Riley, 2011; Dumay, 2012; Pate et al., 2010; Sheehan et al., 1999), but only a few of these examine this performance derailing phenomenon in a university or higher education setting (Thomas, 2005). Makerere University, as a premier institution of higher learning in the eastern and central African region, ${ }^{1}$ seeks to position itself as a leading institution of academic excellence and innovations in Africa. Achieving this endeavour anticipates a culture of trust, fairness, empathy, effective communication, acceptance, and ownership, which drive human and organizational achievement. However, there have been increasing concerns in the university over the prevalence of different forms of ill-treatment and frustration perpetuated, especially by senior academic staff against the junior - which typifies bullying against the revered canons of good employment relations.

This study is also timely as Makerere University has just undergone restructuring of faculties and institutes into a collegiate system, resulting into a new structure and management teams. Intranet has, in this regard, been awash with complaints, accusations, and counter accusations with regard to the leadership of colleges. Pertinently, organizational changes, especially restructuring and re-organisation when not properly handled, have been decried as precursors to bullying in the workplace (Thomas, 2005; Dumay \& Marini, 2012), a scenario which creates a favourable context for this study.

The study thus sought to examine the nature of existing employment relations among staff and prevalence of different elements of bullying and mobbing at Makerere University. The paper evaluates the existing supportive systems to deal with bullying and analyses the impact of bullying on employment relations. Further, the possible ways of enhancing collegial employment relations are presented.

\section{Conceptual and Theoretical Highlights}

Literature on employment relations describes the interactions that exist between the employer and the employees in a workplace. Strong functioning of human resources is largely hinged on the same factors underpinning employment relations such as pay, employment practices, terms and conditions of employment, employee voice through decision making, and open channels of communication (Armstrong, 2009). As Srivastava (2007) explained, this relationship is premised on adjustable mutual interests and goals with economic, social, and psychological satisfaction of the parties as the antecedent factors. Therefore, this means that managers of organizations should focus on practices that enhance cooperation and satisfaction of parties (employers, managers, and larger employee workforce) as this is likely to enhance morale, commitment, productivity and minimise grievances, as well as costs associated with labour (Armstrong, 2009).

Cultivating sound employment relations underscores elements such as delegation, motivation, job enrichment, autonomy, self-leadership, and participative management that buttress good communication and empowerment (Armstrong, 2009). Effective communication cultivates good interpersonal relations and teamwork achievement, while empowerment prompts a change in managerial attitude, which emphasizes a 'triple win' situation whereby the manager wins by delegating, the organisation wins by improving processes, and the employee feels as the primary winner with the leverage to innovate and make decisions (Olsson, 1996). Thus, employment relations and empowerment place people at the centre of the circle rather than on the fringes (Ongori \& Shunda, 2008) where bullying certainly relegates them.

However, the above elements continue to elude empirical practice of modern organisations and bullying continues to thrive as a norm, rather than the exception (Jaw \& Lui, 2003; Lopez et al., 2006), against the backdrop that castigates the conventional management styles of strict-superior subordinate relations and centralized control of decision-making. Interestingly, institutions of higher learning are not immune to bullies (Cassell, 2011) despite the perception that associates higher academic stature and intellectual resonance to lower prevalence of this form of harassment or discrimination.

Whereas there is no universal definition, bullying generally involves meting out of behavioural patterns that intimidate, offend, degrade, humiliate, undermine, or threaten another person, often perpetrated by a stronger

\footnotetext{
${ }^{1}$ Makerere is currently ranked ninth position in African Top Universities and Number one outside South Africa, according to Webometrics ranking July 2013, see http://www.webometrics.info/en/Ranking_africa
} 
personality or one in assumed position of power, authority, or advantage. There is a multiplicity of behavioural descriptions associated with the notion, including, "interpersonal mistreatment, psychosocial harassment, psychological violence, abusive workplace conduct, antisocial employee behaviour, escalated incivility, and psychological aggression, among others" (Thomas, 2005; Von Bergen et al., 2006; Cassell, 2011; Casimir et al., 2012).

Von Bergen et al. (2006) describes bullying as "harassment that inflicts a hostile work environment upon an employee by a co-worker or co-workers, typically through a combination of repeated, inappropriate, and unwelcome verbal, nonverbal, and/or low-level physical behaviours that a reasonable person would find threatening, intimidating, harassing, humiliating, degrading, or offensive."

Deducing from the above, bullying can be physical or psychological and can thus be overt or covert. Overt involves aggressive, abusive, or offensive language, threatening gestures, constant unreasonable criticisms or actual violence. Covert may involve deliberate exclusion, isolation, or alienation of the employee from normal work interaction or opportunities, placing unreasonably high work demands, allocation of demeaning jobs or meaningless tasks, or deliberately withholding information that is intended to make one suffer or lose out.

However, bullying should not be misconceived as single or isolated incidents of misunderstanding, clash of personalities, or miscommunication - nor should it be confused with "joking" or "horseplay" which are characterised by the lack of animosity (Namie, 2003). Similarly, bullying does not refer to regular superior/supervisor instructions, direction, conducting performance audit, invoking policy, or procedural sanctions for misconduct and unsatisfactory performance. Nonetheless, supervisors and managers are expected to offer constructive advice and direction to subordinates in a way that rekindles goodwill and is not purposely demeaning.

The dangers of bullying in the workplace include absenteeism, reduced staff productivity and motivation, and loss of experienced and skilled staff through resignation. Bullying may also have significant social and health costs for individual staff, including loss of confidence, increased anxiety, depression, and high blood pressure. Bullying can also affect others in the workplace in a similar way, even when they are only witnesses to the bullying and are not subject to the bullying themselves. In addition to productivity and staff turnover setbacks, bullying can lead to wastage of important time for the organisation's management in trying to deal with the problem.

The changing trends in styles of communication and expectations between employers (management) and employees, in the wake of stressful and complex organisational environment have recurring challenges to organisational stability through employment relations. Good employment relations empowers, allows individual volunteerism to idea creation, increases job satisfaction and enables responsiveness to client needs and concerns without unnecessary recourse to the superior authority (Osborne \& Plastrik, 1997).

This study theorises bullying as an antecedent to negative employment relations, which undermines organisational stability and achievement. The prevalence of bullying is conceptualised in a three-paradigmatic manifestation comprising inaction, subtle action, and action, as proposed in Cassell's (2011) model (Figure 1). 


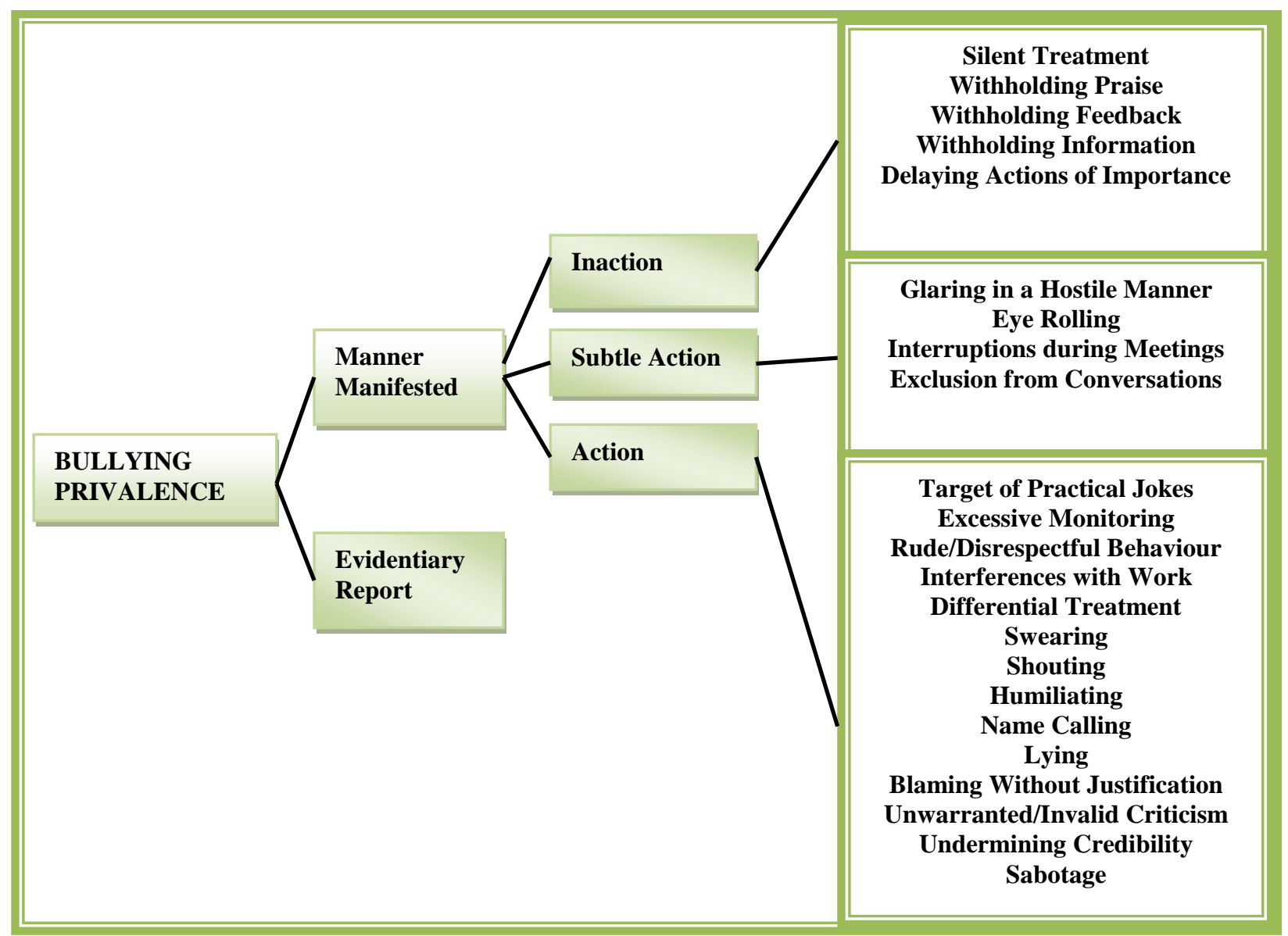

Figure 1: Prevalence of Academic Bullying/Mobbing - Adapted From Cassell (2011)

\section{DATA AND METHODS}

The study is based on primary data sourced from a sample of 102 academic staff of Makerere University. The survey was a cross-sectional study employing a mixed approach to data and methods. First, quantitative data were obtained using self administered questionnaires covering four major themes: (1) academic staff characteristics, (2) general employment aspects and relations, (3) bullying, and (4) collegial relations and support systems. Bullying in this study was assessed based on three major dimensions; namely, inactions, actions, and subtle action.

Collegial relations and support systems were evaluated in the study using a number of items or questions assessed on a five-point Likert scale. Both summative and average indices (scales) were generated in the assessment as measures of the various latent constructs; i.e., bullying (actions, inactions, and subtle actions), collegial relations, and support systems. Second, qualitative data were obtained using key informant interviews.

In the analysis, a descriptive summary of staff characteristics, general employment aspects, bullying, collegial relations, and support system aspects was made using frequency distributions and summary statistics where applicable. Relationships between bullying, support systems, and collegial relations were investigated using the Spearman's Rank correlation, a non-parametric approach. The assessment in this section is based on the indices generated for each of the aspects. Choice of adopting a non-parametric approach in the analysis is based on the fact that the indices do not represent real values. As a matter of fact, the responses on each of the aspects and/or items were regarded as ordinal outcomes. Thus, application of the Pearson correlation may yield misleading conclusions about the data. Associations between the aspects were determined at 5\% $(\mathrm{p}<0.05)$ and $1 \%(\mathrm{p}<0.01)$ levels of significance, unless otherwise stated. 


\section{RESULTS}

The analysis relates to a sample of 102 academic staff of Makerere University. The characteristics of these staff are summarized as follows: predominantly males (74.0\%), having a Masters (62.4\%) degree as their highest academic qualification, followed by $28.7 \%$ with doctorates, while the rest had a Bachelor's Degree. With regard to highest academic rank attained, the highest proportion was Assistant Lecturers (56.7\%), followed by lecturers $(19.2 \%)$, while the rest were mainly teaching assistants. Slightly over five-in-every ten (57.8\%) were in their 30s with regard to age, while the rest were either above $40(26.5 \%)$ or $30(15.7)$ years.

\section{Employment Aspects and Relations}

Tables 1 and 2 present a descriptive summary of aspects on general employment aspects and relations.

Table 1: Distribution of Staff by Their Status of Receipt of Orientation on Job

\begin{tabular}{|l|c|c|}
\hline \multicolumn{1}{|c|}{ Response } & n & Percentage (\%) \\
\hline Yes & 35 & 34.3 \\
\hline No & 67 & 65.7 \\
\hline Total & 102 & 100 \\
\hline
\end{tabular}

Table 2: Distribution of Responses on Selected Employment Aspects and Relations

\begin{tabular}{|c|c|c|c|c|c|}
\hline \multirow{2}{*}{ Employment Aspects And Relations } & \multirow{2}{*}{$\mathbf{n}$} & \multicolumn{4}{|c|}{ Response $(\%)$} \\
\hline & & GE & SE & $\mathbf{N}$ & NT \\
\hline Received orientation from academic unit & 102 & 26.7 & 12.9 & 44.6 & 15.8 \\
\hline Have a clear contract and terms from unit/university & 102 & 6.9 & 6.9 & 32.7 & 53.5 \\
\hline Have clear job description/roles well stipulated & 102 & 6.9 & 2.0 & 37.3 & 53.9 \\
\hline I am aware about reporting channels in my unit & 102 & 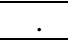 & 3.9 & 21.6 & 74.5 \\
\hline I enjoy cordial relations with senior staff at unit & 102 & 2.9 & 2.0 & 42.2 & 52.9 \\
\hline I enjoy cordial relations with peers at unit & 102 & 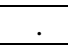 & 2.0 & 23.0 & 75.0 \\
\hline
\end{tabular}

Note: GE - Great Extent, SE - Some Extent, N - Neutral, and NT - Not at All

In the results according to Table 1, less than three-in-every-ten (26.7\%) academic staff affirmed to receiving orientation on the job. The figure points to a low proportion of staff that is oriented in their work in the various academic units. In light of the low proportion of staff receiving orientation on the job, the results on employment aspects and relations are not surprising. A considerable proportion reported not having clear job descriptions (53.9\%), unaware of reporting channels (74.5\%), as well as having clear contracts and terms of service $(53.5 \%)$. The situation was not any different with regard to enjoying cordial relations with senior and peers in the academic units. Results, according to Table 2, reveal that slightly more than half (53\%) do not enjoy cordial relations with senior staff in their units; likewise, the majority (75\%) do not enjoy cordial relations with their peers.

\section{Status of Bullying in Academia}

Views were sought from the academic staff regarding bullying. Particularly, their views on what they considered to be bullying were sought. Figure 2 presents frequency distributions on what staff considered to be bullying. 


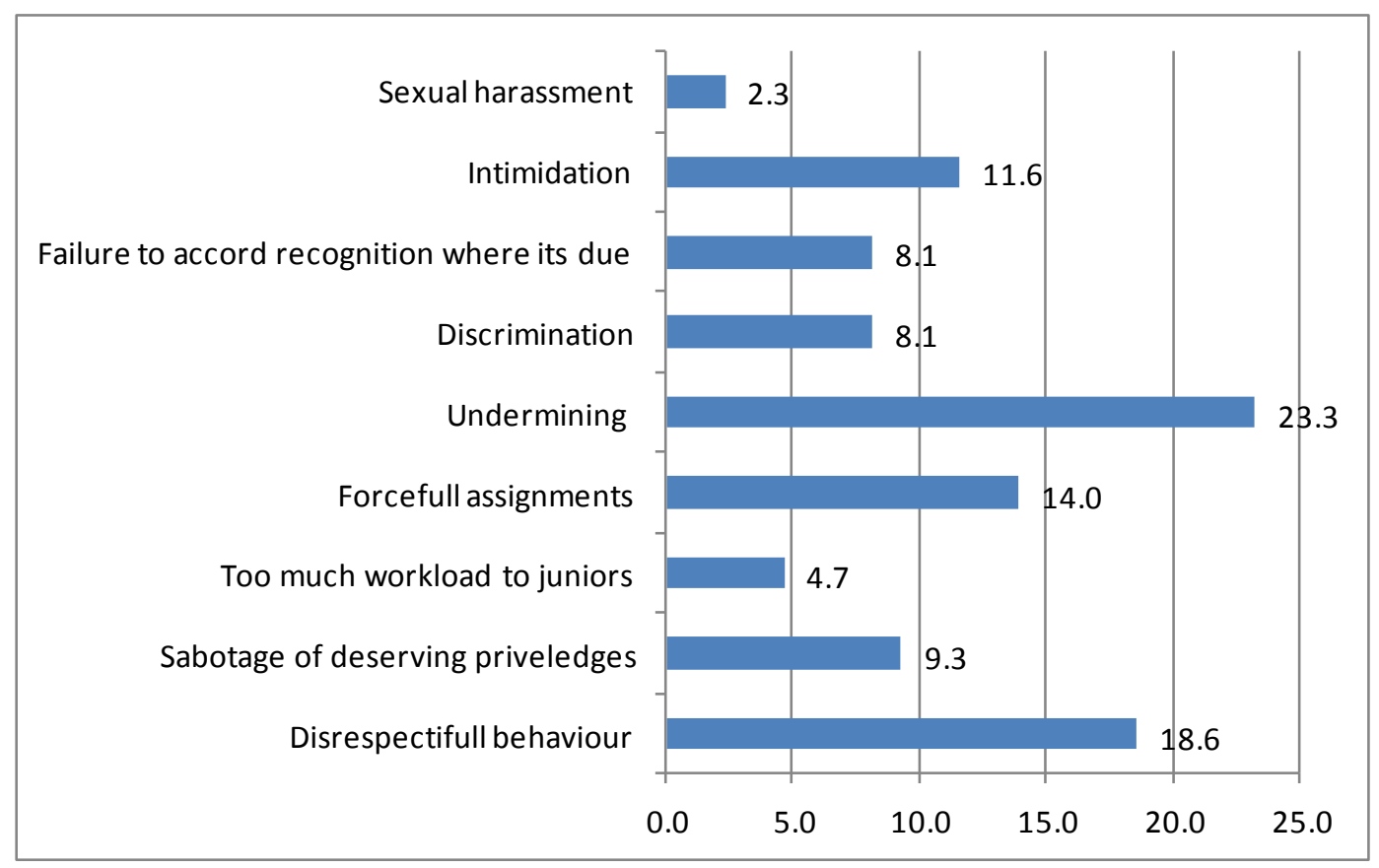

Figure 2: Perception on Bullying Among Academic Staff

In the results, according to Figure 2, the highest proportions of injustices reported were in the area of undermining $(23.3 \%)$ followed by disrespect from other staff $(18.6 \%)$. In a further analysis, slightly more than half $(53.3 \%)$ of the staff affirmed to experiencing any of the aforementioned forms of injustice. The perpetrators of the injustices were predominantly higher rank staff (60.8\%), followed by same ranking staff $(24.6 \%)$, while the rest were lower and other staff in the unit.

The fact that academic institutions are unique, bullying may not usually take on the forms illustrated in Figure 2. Bullying, in this study, is investigated in three major dimensions; namely, inactions, actions, and subtle actions. Tables 3-5 present responses of academic staff regarding their experiences with the various dimensions of bullying.

Table 3: Descriptive Summary of Responses on Inactions

\begin{tabular}{|l|c|c|c|}
\hline \multicolumn{1}{|c|}{ Inactions } & \multirow{2}{*}{ n } & \multicolumn{2}{c|}{ Response (\%) } \\
\cline { 2 - 4 } & & Yes & No \\
\hline Silent treatment or being ignored & 102 & 43.1 & 56.9 \\
\hline Withholding praise or acknowledgment of outstanding contribution & 102 & 44.5 & 55.5 \\
\hline Withholding feedback & 102 & 51.5 & 48.5 \\
\hline Withholding information & 102 & 56.4 & 43.6 \\
\hline Delaying action of importance & 102 & 59.8 & 40.2 \\
\hline
\end{tabular}

Table 4: Descriptive Summary of Responses on Subtle Actions

\begin{tabular}{|l|c|c|c|}
\hline \multicolumn{1}{|c|}{ Subtle Actions } & \multirow{2}{*}{ R } & \multicolumn{2}{c|}{ Response (\%) } \\
\cline { 3 - 5 } & & Yes & No \\
\hline Glaring in hostile manner & 102 & 22.5 & 77.5 \\
\hline Eye rolling & 102 & 17.7 & 82.3 \\
\hline Interruptions during meetings & 102 & 40.0 & 60.0 \\
\hline Exclusion from conversation & 102 & 34.6 & 65.4 \\
\hline
\end{tabular}


Table 5: Descriptive Summary of Responses on Inactions

\begin{tabular}{|c|c|c|c|}
\hline \multirow{2}{*}{ Actions } & \multirow{2}{*}{$\mathbf{n}$} & \multicolumn{2}{|c|}{ Response (\%) } \\
\hline & & Yes & No \\
\hline Target of practical or demeaning jokes & 102 & 31.4 & 68.6 \\
\hline Excessive monitoring & 102 & 19.8 & 80.2 \\
\hline Forceful mentoring & 102 & 20.8 & 79.2 \\
\hline Rude/disrespectful behaviour & 102 & 30.4 & 69.6 \\
\hline Interference with work & 102 & 33.0 & 67.0 \\
\hline Differential treatment & 102 & 24.7 & 75.3 \\
\hline Blaming without justification & 102 & 39.2 & 60.8 \\
\hline Unwarranted/Invalid criticisms & 102 & 37.6 & 62.4 \\
\hline Demand to address persons by their titles (Dr., Prof., etc....) & 102 & 21.8 & 78.2 \\
\hline Undermining credibility & 102 & 30.7 & 69.3 \\
\hline Denying/sabotage of privileges that are rightfully expected & 102 & 48.5 & 51.5 \\
\hline
\end{tabular}

Results in Tables 3-5 show high prevalence of inactions compared to subtle actions and those among academic staff at the university. The main forms of inactions were delaying of action of importance (59.8\%), withholding information $(56.4 \%)$, and withholding feedback $(51.5 \%)$. With regard to subtle actions, interruptions during meetings $(40.0 \%)$ and exclusion from conversations (34.6\%) were the main prevalent forms. On the other hand, predominant forms of actions were sabotage of privileges (48.5\%), blaming without justification (39.2\%), and unwarranted/invalid criticisms (37.6\%).

The fact that the proportion of staff experiencing some form of inaction is above the figure that reported having experienced any form of bullying (53.3\%) implies that many of these individuals are not entirely aware of these unjust treatments. These findings affirm the existence of bullying in the academia, but a number of people experience it unknowingly.

\section{Support Systems in Units}

Responses were sought regarding the existence of support systems for dealing with the actions, subtleactions and inaction. Table 6 presents responses on perceptions regarding existence of support systems for dealing with bullying in the academic units.

Table 6: Distribution of Responses on Support Systems in the Units

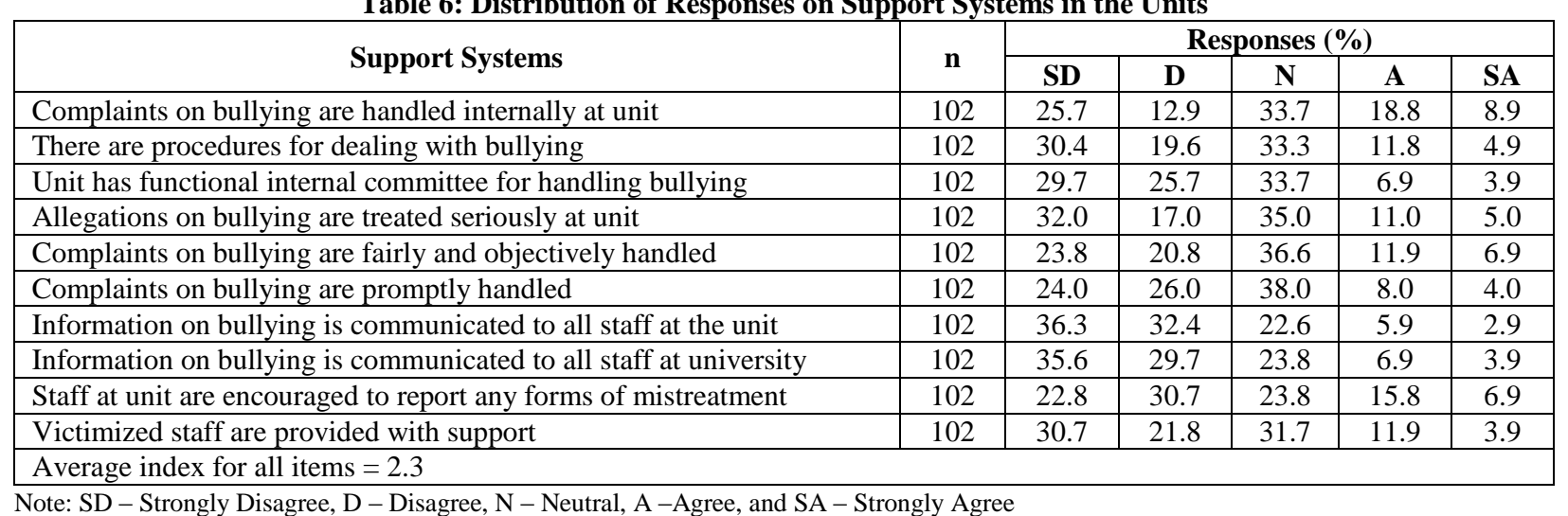

Overall, the highest proportions of academic staff were either undecided or in disagreement with regard to existence of support systems for dealing with bullying in their academic units. The disagreement was mainly in the following aspects: communication to all staff on issues related to bullying at the university (65.3\%) and academic units (68.7\%); existence of functional internal committee for handling bullying in the unit (55.4\%). On the other hand, the uncertainty was mainly noted in the aspects of fairness and objectiveness in handling of bullying complaints (36.6\%), promptness in handling the complaints (38.0\%), and seriousness with regard to treatment of 
bullying cases $(35.0 \%)$. In other words, a low mean index of aspects in this theme implies a dearth of support systems for handling bullying cases in the academic units.

\section{Collegial Relations in Unit}

Views were sought from the academic staff regarding their satisfaction with collegial relations shared, particularly with senior staff in their respective units. Table 7 presents responses on perceptions regarding collegial relations among staff in the academic units.

Table 7: Descriptive Summary of Responses on Satisfaction with Collegial Relations in the Units

\begin{tabular}{|c|c|c|c|c|c|c|}
\hline \multirow{2}{*}{ Collegial Relations Aspects } & \multirow{2}{*}{$\mathbf{n}$} & \multicolumn{5}{|c|}{ Response (\%) } \\
\hline & & VD & $\mathbf{D}$ & $\mathbf{N}$ & $\mathbf{S}$ & VS \\
\hline Collegial relations with senior staff & 102 & 3.9 & 6.9 & 17.8 & 48.5 & 22.7 \\
\hline Social support obtained from senior staff & 102 & 3.9 & 18.8 & 17.8 & 43.6 & 15.8 \\
\hline Relations with administration and management & 102 & 4.0 & 10.1 & 17.2 & 51.5 & 17.7 \\
\hline Recognition by senior staff of efforts and success & 102 & 4.9 & 11.8 & 22.6 & 43.1 & 17.7 \\
\hline Recognition by academic unit of efforts and success & 102 & 4.9 & 14.8 & 20.8 & 45.5 & 13.9 \\
\hline Overall freedom in teaching & 102 & 3.0 & 3.0 & 12.0 & 43.0 & 39.0 \\
\hline Professional interaction with senior staff & 102 & 3.9 & 9.9 & 17.8 & 43.6 & 24.8 \\
\hline Personal interest shown and friendliness by senior staff & 102 & 2.9 & 7.8 & 15.7 & 50.0 & 23.5 \\
\hline Respect from senior staff & 102 & 3.9 & 4.9 & 12.8 & 52.7 & 25.7 \\
\hline
\end{tabular}

Note: VS - Very Satisfied, S - Satisfied, N - Neutral, D - Dissatisfied, and VD - Very Dissatisfied

Overall, the staff were satisfied with collegial relations in their academic units. Particularly, the evidence is demonstrated in the results by high responses regarding collegial relations with senior staff (71.2\%), having freedom in teaching $(82.0 \%)$, professional interaction $(68.4 \%)$, receiving respect $(78.4 \%)$, as well as personal interest and friendliness by senior staff $(73.5 \%)$. The debatable aspects concerning collegial relations enjoyed with senior staff were recognition by senior staff and academic units with regard to individual efforts and success attained, as well as receipt of social support.

\section{Collegial Relations and Bullying}

Investigations were made regarding the relationships between collegial relationships and bullying. As earlier indicated, summative scores or indices on dimensions of bullying, existence of support systems and collegial relations were adopted in the investigations at this stage. Table 8 presents correlation estimates between the various dimensions of bullying, collegial relations, and support systems.

Table 8: Inter-Correlations of Collegial Relations and Bullying

\begin{tabular}{|l|c|c|c|c|c|}
\hline \multicolumn{1}{|c|}{ Measures } & $\mathbf{1}$ & $\mathbf{2}$ & $\mathbf{3}$ & $\mathbf{4}$ & $\mathbf{5}$ \\
\hline 1. Inactions & $\mathbf{1 . 0}$ & & & & \\
\hline 2. Subtle-actions & $0.609^{* *}$ & $\mathbf{1 . 0}$ & & & \\
\hline 3. Actions & $0.650^{* *}$ & $0.687^{* *}$ & $\mathbf{1 . 0}$ & $\mathbf{1 . 0}$ & \\
\hline 4. Support systems & $-0.271^{*}$ & $-0.328^{* *}$ & $-0.272^{*}$ & -0.172 & $\mathbf{1 . 0}$ \\
\hline 5. Collegial Relations & $-0.471^{*}$ & $-0.268^{*}$ & $-0.430^{* *}$ & -172 \\
\hline
\end{tabular}

Note: Assessment is based on Spearman's Rank correlation; where, $* \mathrm{p}<0.05$ and $* * \mathrm{p}<0.01$

The findings, according to Table 8, reveal significant associations established between the various dimensions of bullying, collegial relations, and existence of support systems ( $\mathrm{p}<0.05$ ). These findings are summarized as follows:

1. There were strong positive correlations between the occurrence of inactions, subtle-actions, and actions related to bullying. In other words, staff who reported high occurrence of actions, likewise, reported a high occurrence of inactions. The same argument holds with regard to actions and subtle-actions as well as subtle actions and inactions. 
2. Satisfaction with collegial relations was negatively associated with occurrence of actions, inactions, and subtle-actions related to bullying. Staff who reported a high occurrence of actions, inactions and subtle actions related to bullying reported a low satisfaction of collegial relations with senior staff.

3. Existence of support systems was negatively associated with occurrence of subtle-actions, actions, and inactions related to bullying. Staff who reported a high occurrence of actions, inactions, and subtle actions related to bullying reported a low existence of support systems for dealing with the injustices in their respective units.

\section{DISCUSSION}

In the findings, while the proportion of staff who reported to have experienced bullying is $53.3 \%$, the figure could actually be higher if we considered the hardly noticeable, but inappropriate bullying behaviours that are reported as inactions. As a matter of fact, a further assessment based on the dimension of inaction (Cassell, 2011) reveals a higher proportion reporting information being withheld (56.5\%) and those where action of importance was delayed (60\%) for some reason. This evidence suggests that a considerable number of academic staff experience the various forms of injustice unknowingly. The fact that the significant correlations were established between the dimensions of inactions, actions, and subtle-actions related to bullying suggests a chain of injustices being experienced by several academic staff at the university. Certainly, Cassell's (2011) argument of institutions of higher learning not being immune toward bullies is highly supported.

However, the low response regarding the existence of support systems for dealing with bullying (inactions, actions, subtle-actions) worsens the situation. The large proportion of staff that were undecided regarding the existence of support systems in their units to deal with bullying actually spells doom. A considerable proportion of staff interviewed decried the general lack of institutionalised system of inducting new employees in the university. The counselling services are scanty as the university of more than 45,000 students and staff population has just one centralised counselling unit with hardly more than two professionals. Counselling services are nonexistent at the academic units. ${ }^{2}$ Other respondents interviewed were concerned that ascending to academic leadership positions in the university only requires one to have attained a rank of Senior Lecturer and above, with hardly any consideration of previous managerial experience or training qualification in management, and once people are in such positions, there is no effort to have them trained in basic leadership and management skills. ${ }^{3}$

The bullying culture has thrived in Makerere on the deficiencies arising from poor legal framework and policies in place, leadership styles of some people in leadership positions that worship the strict superior-subordinate relationship and centralised control of decision-making, and nature of the working environment characterised by increasing workload and pressure, as well as the scrambling for the meagre resources among staff members that give a leeway to patronage. ${ }^{4}$

This evidence suggests that a relatively large number of these injustices go unresolved in the academic units. It is therefore not surprising that some academic staff members in Makerere have resorted to courts of law to solve issues that would ideally have been handled internally by the statutory organs of the university. Indeed, Dumay and Marini (2012) decries the email communication and other media as other newer forms of bullying. The episodes of open staff attacks and vengeance feature regularly on staff intranet and during Makerere University Academic Staff Association (MUASA) meetings as well as in colleges and schools' meetings. ${ }^{5}$

While studies indicate that anyone can be targeted for bullying in their course of work, including professors and senior lecturers, the prime perpetrators of these injustices are consensually regarded to be senior staff (Casimir et al., 2012; Cassell, 2011; Thomas, 2005). This study did not reveal otherwise regarding this issue. Similar to the situation in many academic institutions, senior staff are usually in top administrative and management positions in the academic units and institutions. Thus, this evidence further suggests that there is a higher likelihood of many

\footnotetext{
${ }^{2}$ Interview, Official, Makerere Academic Staff Association (MUASA)

${ }^{3}$ Interview, Senior academic members, Makerere University

${ }_{5}^{4}$ Interview, Official, MUASA

${ }^{5}$ Interview, Official, MUASA
} 
such bullying cases going unresolved since the perpetrators of these injustices are the same ones mandated with the responsibility of resolving these issues.

Worth noting is the negative correlation noted between the occurrence of inactions, actions, and subtleactions related to bullying and collegial relations with senior staff in the academic units. This evidence implies that bullying impacts negatively on collegial relations between junior and senior academic staff at the university. Regarding the negative impacts of the injustices, Gumbas and Meglich (2012) argue that bullied workers tend to become psychologically dejected, stressed at work, less committed to the workplace, and often quit their jobs.

\section{CONCLUSIONS}

This paper has demonstrated that employee performance is hinged on the bond and workplace collegial relations that evolve between superiors and subordinates and amongst individual staffing colleagues. This bond is often heralded by effective communication, feedback systems, and empowerment, which help to establish a culture of exchange and mutuality within organisations. The paper further highlights that bullying practices are antecedent to poor employment relationships.

The study reveals prevalence of bullying and mobbing in Makerere University academic units with varying manifestations, dimensions, and perception. The deplorable behaviour has thrived on the deficiencies arising from poor legal framework and policies in place, leadership styles of those in management that worship the strict superior-subordinate relationship and centralised control of decision-making, and nature of the working environment characterised by scanty resources and facilitation support to task holders. However, the findings are limited in explaining variations (if any) in the occurrence of bullying by academic units and/or discipline area. Thus, an assessment involving a larger sample clustered by discipline area and academic units would go a long way in providing a deeper understanding the injustices in academia.

Nevertheless, the findings point to the need to create a respectful organizational culture that fortifies collegial and harmonious coexistence through policy and open systems of communication with empowerment and participatory decision-making. There is need to strengthen the university human resources policy and manuals to reinforce good employment relations through clearly defining bullying, stipulating clear procedure for raising and handling complaints, and effectively disciplining perpetrators. There is need for scheduled refresher training for all employees to set the tone for behavioural expectations in the workplace. College, school, and departmental management commitment is critical, along with enforcement, at the supervisory level. Academic managers and staff should be trained to understand the policy and enforce it with staff without fear or favour. Additional strategies include having peer listeners attached to departments who are selected and trained to provide assistance to coworkers, designating an ombudsperson and departmental counsellors, and providing management skills training to all supervisory staff. All effort should be made to invigorate rigorous academic debate, research, and other scholarly endeavours, which promote intellectual resonance as opposed to schemes of undermining and patronising practices.

\section{AUTHOR INFORMATION}

Umar Kakumba, Ph.D., is a Senior Lecturer and Dean, School of Business, College of Business and Management Sciences, Makerere University, Uganda, where he teaches undergraduate and graduate courses in human resource management, organisational theory, public sector, and policy and development management. He is also a CAPREx Fellow at the Centre of Development Studies, Cambridge University in the UK. E-mail: ukakumba@bams.mak.ac.ug (Corresponding author)

Robert Wamala, Ph.D., is a Senior Lecturer in the School of Statistics and Planning, College of Business and Management Sciences, Makerere University, where he teaches, conducts research and has published in a wide range of areas including statistics, applied economics, business, population, and higher education studies. E-mail: rwamala@bams.mak.ac.ug

Seperia Bwadene Wanyama is an Assistant Lecturer in the School of Business, College of Business and Management Sciences, Makerere University, Uganda, where he teaches courses in human resource management, organisational theory \& management, and public sector management. E-mail: $\underline{\text { swanyama@ bams.mak.ac.ug }}$ 


\section{REFERENCES}

1. Armstrong, M. (2009). Handbook of human resource management practice (11 $1^{\text {th }}$ ed.). New York: Prentice Hall.

2. Casimir, G., McCormack, D., Djurkovic, N., \& Nsubuga-Kyobe, A. (2012). Psychosomatic model of workplace bullying: Australian and Ugandan schoolteachers. Employee Relations, 34(4), 411-428.

3. Cassell, M. A. (2011). Bullying in academia: Prevalent, significant, and incessant. Contemporary Issues in Education Research, 4(5), 33-44.

4. Cole, G. A. (2004). Management theory and practice (6 ${ }^{\text {th }}$ ed.). BookPower Publications: London.

5. Cunningham, I. (2008). Viewpoint: Is honest feedback always a good idea? And why is there concern about bullying? Development and Learning in Organizations, 22(1), 5-7.

6. Dumay, J., \& Marini, L. (2012). Bullying in context: A risk management perspective. Journal of Human Resource Costing \& Accounting, 16(4), 281-301.

7. Gibson, L. J. (1997). Organizations: Behavior, structure, processes. McGraw-Hill: New York.

8. Gumbus, A., \& Meglich, P. (2012). Lean and mean: Workplace culture and the prevention of workplace bullying. Journal of Applied Business and Economics, 13(5).

9. Lopez, S. P., Peon, J. M., \& Ordas, C. J. (2006). Human resource management as a determining factor in organizational learning. Management Learning, 37(2), 215-39.

10. Namie, G. (2003). Workplace bullying: Escalated incivility. Ivey Business Journal, 1, 6.

11. Olsson, J. (1996). Employee empowerment: A crucial ingredient in a total quality management strategy. Retrieved 11/11/2011 from http://www.geocities.com/TimesSquare/1848/index.html

12. Ongori, H., \& Shunda, J. P. W. (2008). Managing behind the scenes: Employee empowerment. The International Journal of Applied Economics and Finance, 2, 84-94.

13. Osborne, D., \& Plastrik, P. (1997). Banishing bureaucracy: The five strategies for reinventing government. New York: Penguin Group.

14. Pate, J., \& Beaumont, P. (2010). Bullying and harassment: A case of success? Employee Relations, 32(2), 171-18.

15. Riley, D., Duncan, D. J., \& Edwards, J. (2011). Staff bullying in Australian schools. Journal of Educational Administration, 49(1), 7-30.

16. Sheehan, M., Barker, M., \& Rayner, C. (1999). Applying strategies for dealing with workplace bullying. International Journal of Manpower, 20(1/2), 50-56.

17. Storey, J. (ed). (2001). Human resource management. New Perspectives, London: Thomson Learning.

18. Thomas, M. (2005). Bullying among support staff in a higher education institution. Health Education, 105(4), 273-288.

19. Von Bergen, C. W., Zavaletta, J. A., \& Soper, B. (2006). Legal remedies for workplace bullying: Grabbing the bully by the horns. Employee Relations Law Journal, 32(3), 14-41. 


\section{NOTES}

